\title{
RESUMO
}

ISSN Impresso: 2316-3321

DOI: 10.17564/2316-381X.2020v8n2p28-45
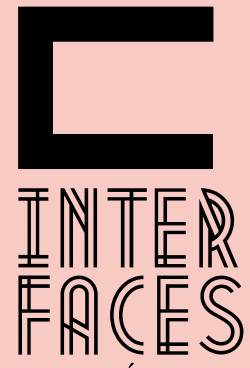

CIENTÍFICAS

\section{CONTRIBUIÇÕES DO DEBATE ENTRE NANCY FRASER E AXEL HONNETH PARA A JUSTIÇA ENTRE GÊNEROS}

\section{CONTRIBUTIONS OF THE DEBATE BETWEEN NANCY FRASER AND AXEL HONNETHFOR GENDER JUSTICE}

CONTRIBUCIONES DEL DEBATE ENTRE NANCY FRASER Y AXEL HONNETH PARA LA JUSTICIA DE GÉNERO.
Ariella Ferreira da Mota ${ }^{1}$ Jussara Maria Moreno Jacintho ${ }^{2}$
0 presente artigo tem o objetivo de analisar convergências e divergências entre as concepções de justiça de Nancy Fraser e de Axel Honneth, a fim de apurar em que medida o debate entre eles oferece um aporte substantivo para a igualdade de gênero. Para tanto, contextualiza-se brevemente o feminismo, e, mediante revisão bibliográfica e pelo método crítico-analítico, coteja-se a teoria de justiça de Nancy Fraser, baseada na redistribuição, reconhecimento e representação, com a teoria do reconhecimento de Axel Honneth, reformulada, em parte, pelo seu "Direito da Liberdade". Como resultado, verifica-se uma complementaridade entre ambos, no sentido de que Nancy Fraser oferece diagnósticos a respeito de falhas dos movimentos feministas contemporâneos no atendimento de demandas atuais, ao tempo em que as esferas de reconhecimento de Axel Honneth oferecem uma alternativa suprir tais falhas.

\section{PALAVRAS-CHAVE}

Justiça. Feminismo. Reconhecimento. 


\section{ABSTRACT}

This article aims to analyze convergences and divergences between the conceptions of justice by Nancy Fraser and Axel Honneth, in order to determine to what extent the debate between them offers a substantive contribution to gender equality. To this end, feminism is briefly contextualized and, through bibliographic review and the critical-analytical method, Nancy Fraser's theory of justice, based on redistribution, recognition and representation, is compared with Axel Honneth's theory of recognition, reformulated, in part, by its "Right to Freedom". As a result, there is a complementarity between both, in the sense that Nancy Fraser offers diagnoses regarding the failures of contemporary feminist movements in meeting current demands, while Axel Honneth's spheres of recognition offer an alternative to fill those failures.

\section{KEYWORDS}

Justice. Feminism. Recognition.

\section{RESUMEN}

Este artículo tiene como objetivo analizar las convergencias y divergencias entre las concepciones de justicia de Nancy Fraser y de Axel Honneth, a fin de determinar en qué medida el debate entre ellas ofrece una contribución sustantiva a la igualdad de género. Con este fin, el feminismo se contextualiza brevemente y, a través de la revisión bibliográfica y el método crítico-analítico, la teoría de la justicia de Nancy Fraser, basada en la redistribución, el reconocimiento y la representación, se compara con la teoría del reconocimiento de Axel Honneth, reformulado, en parte, por su "Derecho a la Libertad". Como resultado, existe una complementariedad entre ambos, en el sentido de que Nancy Fraser ofrece diagnósticos sobre las fallas de los movimientos feministas contemporáneos para satisfacer las demandas actuales, mientras que las esferas de reconocimiento de Axel Honneth ofrecen una alternativa para llenar esas fallas.

\section{PALABRAS CLAVE}

Justicia; Feminismo; Reconocimiento. 


\section{INTRODUÇ̃̃̃O}

O presente artigo tem o objetivo de analisar convergências e divergências entre as concepções de justiça de Nancy Fraser e de Axel Honneth, a fim de apurar em que medida o debate entre eles oferece um aporte substantivo para a igualdade de gênero.

Após uma breve contextualização histórica do movimento feminista, ressaltando a análise de Nancy Fraser sobre a segunda onda do feminismo, faz-se uma revisão bibliográfica de sua teoria de justiça, baseada na conjugação de critérios de redistribuição e reconhecimento, confrontando-a com parte da produção teórica de Axel Honneth. Em seguida, coteja-se a reformulação da teoria de justiça de Nancy Fraser, modificada pela inclusão da dimensão política e do critério da representação, com a teoria do reconhecimento de Axel Honneth, reformulada, em parte, pelo seu "Direito da Liberdade".

Pelo método crítico-analítico, constata-se que a concepção de reconhecimento de Nancy Fraser é diversa da teoria do reconhecimento de Axel Honneth, deflagrando divergências de pensamento e de método entre ambos. Enquanto Nancy Fraser busca critérios de justiça que possam dimensionar o "quê", o "quem" e o "como" da justiça em busca da paridade de participação, Axel Honneth elabora uma teoria que busca a emancipação do indivíduo por meio do reconhecimento social. Ambos os autores, contudo, empreendem uma análise do social com o objetivo de transformar o normativo no sentido de proporcionar o máximo de liberdade individual e inclusão social por meio da intersubjetividade.

Como resultado, a conjugação de ambos permite projetar soluções para o diagnóstico de Nancy Fraser a respeito de uma falha dos movimentos feministas contemporâneos por meio da aplicação das esferas de reconhecimento de Axel Honneth.

\section{CONTEXTUALIZANDO O FEMINISMO}

O Feminismo², aqui tomado como o conjunto de movimentos sociais caracterizados pela busca da igualdade de gênero e da inclusão da mulher nos diferentes espaços sociais ao longo da história em paridade de valor, é dividido em três momentos, denominados as três ondas do feminismo, mais indicativas de uma sucessão de demandas do que indicativos de conquistas; a divisão em ondas não pretende diminuir a peculiaridade de cada movimento feminista em cada período histórico, mas apenas.

Os primeiros movimentos registrados nesse sentido remontam à Declaração de Direitos da MuIher e da Cidadã, de 1791, cuja autoria é atribuída à Marie Gouze, filha de açougueiro no Sul da França, que adotou o pseudônimo de Olympe de Gouges (1748-1793) para assinar panfletos, peças de teatro e divulgar a luta por igualdade de direitos. A Declaração de Direitos da Mulher e da Cidadã

2 "Há clareza que não se pode falar mais de feminismo no singular, haja vista a pluralidade deste movimento que vem penetrando em várias esferas, atingindo públicos os mais diversos. Por essa razão, pode-se afirmar que o feminismo se renovou, ampliou e diversificou. Mas, não se pode deixar de considerar que cada feminismo retrata um contexto, uma época, um estado de espírito, uma maneira de resistir às diversas formas de opressão que as mulheres enfrentam ao longo dos Séculos” (FERREIRA, 2018, p. 49). 
foi uma resposta à Declaração de Direitos do Homem e do Cidadão, de 1789, mas levou Marie Gouze à guilhotina, em 1793, quando teria afirmado: "A mulher tem o direito de subir ao cadafalso; ela deve ter igualmente o direito de subir à tribuna” (ASSMANN, 2007, p. 1).

A primeira onda se iniciara na época de Marie Gouze e do lluminismo, marcada, portanto, pela conquista das liberdades ou direitos individuais e pela redução da desigualdade do valor da mulher em comparação ao homem. A primeira onda passa pela conquista do direito ao voto em alguns países da Europa Ocidental, em fins do século XIX, e nos Estados Unidos em 1919, após o movimento feminista inglês das suffragettes, que fundaram o grupo Women's Social anda Political Union, influenciando o mundo ocidental baseado em propaganda, desobediência civil, não violência ativa e resistência (TEIXEIRA; RODRIGUES, 2018, p. 6).

Portanto, nessa época, a noção de justiça para as mulheres estava associada à conquista da liberdade negativa pela mulher, ou seja, conquista de uma dimensão básica de liberdade, consistente em poder agir sem coação e de estar protegida da ação do outro em uma esfera particular (HONNETH, 2015), mas sempre uma busca por equiparação da mulher aos direitos conquistados pelos homens para os homens em limitação ao poder do Estado.

A segunda onda do feminismo acontece após a Segunda Guerra Mundial, atravessando o declínio econômico das sociais-democracias e dos Estados de Bem-Estar Social da Europa Ocidental e Estados Unidos. Além daquela dimensão inicial de liberdade, em se lutava pelo direito ao voto e pela igualdade dos demais direitos, essa época é marcada pela preocupação com a desigualdade cultural e social ampliando "[...] a discussão para outras questões: sexualidade, família, mercado de trabalho, direitos reprodutivos, desigualdades de fato e desigualdades legais” (TEIXEIRA; RODRIGUES, 2018, p. 7).

Nos anos 1970, fazer justiça remetia a lutas pela institucionalização de políticas públicas e de instrumentos normativos voltados à redistribuição de renda, inclusão social, redução das desigualdades sociais, levando Nancy Fraser a aludir, em exagero propositado 3 , que a vinculação entre justiça e redistribuição de renda nasce com o capitalismo e marca a concepção Keynisiana-westfaliana de Estado (FRASER, 2012).

Modelo Keynisiano porque a intervenção do Estado na economia era assentida pelo capitalismo liberal desde que tivesse a finalidade político-social de garantir o pleno emprego e reduzir as desigualdades pelo estímulo ao consumo que aumentaria a produção industrial, e, consequentemente, o emprego e a renda. Westifaliano porque até a década de 1970 o conceito de soberania de Estados e a concentração das relações sociais no território de cada Estado o tornavam um contexto fechado para análise social.

A crise desse modelo de Estado força a reformulação do projeto Keynisiano de economia que pouco a pouco foi cedendo espaço ao modelo neoliberal, como também forçou o projeto westfaliano de Estado Soberano na organização política mundial que foi pouco a pouco se abrindo e se tornando fluido ou permeável a acontecimentos exteriores ao seu território. Ambos esses movimentos foram impulsionados pela globalização (FRASER, 2012).

3 Diz-se de exagero propositado porque o critério de justiça distributiva é teorizado desde Aristóteles, disputando espaço ou em concorrência com os critérios de justiça comutativa e recíproca, sendo cada um desses critérios adequados para uma situação diversa. Evidentemente, Nancy Fraser não ignora Aristóteles, apenas quer enfatizar que as principais lutas sociais do século XX se fundavam no critério distributivo, que considera justa a adoção de mecanismos para redistribuição de renda ou diminuição das desigualdades independentemente de merecimento ou retribuição ao mérito. 
A representação de justiça como balança, imparcialidade, ponderação de valores em conflito, distribuição equitativa de bens econômicos era adequada à época da Guerra Fria. Esse pressuposto seria compartilhado entre as sociais democracias de primeiro mundo; dentro do comunismo do então chamado segundo mundo e nos países em desenvolvimento do terceiro mundo, de modo que, “[...] o imaginário distributivista hegemônico emprestava certa credibilidade à representação convencional da balança moral" (FRASER, 2012, p. 140).

As lutas por igualdade de gênero teriam se intensificado em movimentos sociais a partir dos anos 1960 , nesse momento do fim da prosperidade das sociais-democracias, pelo que teriam se apropriado, nessa primeira fase, da noção de justiça como redistribuição de renda, com o que as lutas por igualdade de gênero se confundia, num primeiro momento, com lutas de classes ou por desigualdade social.

Ao mesmo tempo surgiram, sobretudo nos Estados Unidos, as lutas contra preconceito de raça e por igualdade de direitos civis, que também serviram de incentivo e de apoio às reivindicações por igualdade de gênero.

Na percepção de Nancy Fraser, as reivindicações contra o racismo e pelo feminismo entre os anos 1960 e 1970 resgataram a ideia de justiça enquanto reconhecimento de origem hegeliana (FRASER, 2012, p. 2200).

Deu-se então uma virada no movimento feminista, o qual deixava de lutar por uma bandeira genérica de "igualdade social e agora investia suas energias em uma mudança cultural [...] (FRASER, 2012, p. 2222).

Na visão de Fraser, essa guinada terminou permitindo que o movimento feminista fosse absorvido pelo neoliberalismo econômico. Deixava-se de lutar por igualdade econômica de todos, para se reivindicar por uma mudança de visão antropocêntrica, pela inclusão da mulher em espaços antes dominados por homens, pela igualdade de valor entre homem e mulher (FRASER, 2012)

Apesar dos ganhos culturais trazidos pelo reconhecimento, Fraser interpreta que essa mudança de substrato teórico enfraqueceu a luta geral por igualdade, servindo como distração e esquecimento de lutas por igualdade social e, por consequência, fortalecendo o neoliberalismo econômico ou deixando de impor obstáculos sociais ou resistência popular ao que chama de "fundamentalismo do livre mercado" (FRASER, 2012).

A partir dessa segunda fase do feminismo, que Fraser denomina de fase da política de identidade, as reivindicações por igualdade de gênero teriam enfatizado o reconhecimento da diferença como pertencente ao campo cultural, deixando a economia e a política como campos apartados das lutas por igualdade de gênero. Nas palavras de Fraser (2012) "cativadas na realidade pela política do reconhecimento, desviamos sem querer a teoria feminista em direção a causas culturais no preciso momento em que as circunstâncias requeriam uma atenção redobrada em direção à política de redistribuição" (FRASER, 2012, p. 2232).

Nas palavras de Nancy Fraser (2009, p. 30):

Um caso paradigmático é o que Susan Okin caracterizou como "um ciclo de vulnerabilidade claramente assimétrica e socialmente provocada pelo casamento". Em que a responsabilidade tradicional das mulheres para o processo de criar e educar os filhos ajuda a moldar os mercados de trabalho que as desfavorecem, resultando em poder desigual no mercado econômico, o que, por sua vez, reforça e exacerba o poder desigual na família. 
(OKIN, 1989, p. 138). Tais processos de subordinação mediados pelo mercado são a própria essência do capitalismo neoliberal.

A terceira fase do feminismo, atualmente vivenciada, é denominada por Nancy Fraser como a "fase da insegurança". Com o fim do estado de bem-estar social, hoje se viveria a fase da insegurança, marcada pela relativização da legislação trabalhista, o emprego múltiplo e desgastante (FRASER, 2012, p. 2233). No Brasil, essa situação de insegurança é intensificada pela deficiência dos sistemas públicos de saúde e de educação, que terminam por sobrecarregar financeira e psicologicamente mães e pais de famílias.

Nos Estados Unidos, Nancy Fraser enxerga hoje o desgaste do feminismo tanto pela perda de ênfase na redistribuição de renda como critério de justiça, como também em uma sensação generalizada de vulnerabilidade da mulher nesses tempos de insegurança, de sociedade de risco.

Essa vulnerabilidade leva a situações paradoxais nas quais muitas vezes a mulher está posicionada como exclusivamente responsável pelo sustento financeiro e emocional da família e, portanto, inserida no contexto do empoderamento feminino, mas, por outro lado, carente de válvulas de escape emocionais capazes de acolher sua vulnerabilidade.

Segundo Nancy Fraser observa, essa vulnerabilidade ou carência muitas vezes é capturada por movimentos religiosos, (nos Estados Unidos, Nancy Fraser alude aos Evangélicos), que suprem essa carência, ocupando o papel de oferecer à mulher acolhimento e segurança emocional necessária para seguir em frente (FRASER, 2012). Nas palavras de Nancy Fraser:

Interessa observar que o evangelismo não dá, em realidade, segurança às pessoas. Mas lhes oferece um discurso e um conjunto de práticas mediante os quais elas podem manejar suas inseguranças. [...] 0 objetivo é, em parte, passar aceitação mas também preparar as pessoas para a turbação própria de tempos difíceis. (FRASER, 2012, p. 2322-2323).

Essa vulnerabilidade financeira e emocional marca a terceira fase do feminismo, cabendo às feministas, na percepção de Nancy Fraser, ocupar esse lugar de acolhimento - que ela entende hoje estar sendo ocupado pelos evangélicos - ocupação que passaria pela necessidade de conjugar as demandas de reconhecimento à demandas de redistribuição de renda e, ainda, a demandas de representação.

Nas seções seguintes, os conceitos de reconhecimento, redistribuição e representação serão brevemente apresentados de modo a se entender como o movimento feminista pode se fortalecer na percepção de Nancy Fraser.

\section{RECONHECIMENTO E REDISTRIBUIÇÃO OU REDISTRIBUIÇÃO COMO RECONHECIMENTO?}

Em debate acerca da suposta insuficiência da Teoria do Reconhecimento para a realização de justiça em demandas sociais alheias ao reconhecimento da diferença, Nancy Fraser acusa Axel Hon- 
neth ${ }^{4}$ de trair suas raízes marxistas, focadas na luta de classes, para passar a defender que justiça se resume a reconhecimento, com o que Axel Honneth teria contribuído para um esquecimento da desigualdade social, atraindo a atenção dos movimentos sociais para questões de gênero, de cultura e identitárias, mas abrindo espaço para o neoliberalismo reduzir a liberdade individual.

Preocupada com a injustiça da desigualdade social e sua propensão para reduzir a força do feminismo, haja vista as interseccionalidades ${ }^{5}$ existentes no mundo real, Nancy Fraser passa então a formular sua própria teoria da justiça, que estaria fincada em dois pilares, quais sejam, redistribuição e reconhecimento. Para Fraser (2003) a estrutura econômica de classes e estamentos, a hierarquia social (ou religiosa, principalmente no mundo árabe) persistia, gerando desigualdades cuja reparação não poderia ser alcançada pelo critério de justiça enquanto reconhecimento.

A interseccionalidade ou a sobreposição de situações de desigualdades excludentes em diferentes dimensões, econômica, de gênero, racial, demandaria, para Fraser, uma teoria bidimensional de justiça, tendo em vista que "[...] nem uma teoria do reconhecimento, nem uma teoria da distribuição podem por si só proporcionar uma compreensão adequada da justiça na sociedade capitalista [...]" (FRASER, 2003, p. 19, tradução livre). Mais tarde, Fraser incorporaria outra dimensão a essa teoria, como se verá nas seções seguintes.

A distinção entre injustiça causada por desigualdade social de injustiça causada por falta de reconhecimento cultural é realizada por Fraser em "Redistribution or Recognition? A political-philosophical Exchange", de 2003. No livro, Fraser discute as bases da teoria de reconhecimento desenvolvida por Axel Honneth, reconstruída a partir de Hegel. Para Fraser, Honneth teria se desviado das raízes marxistas da teoria crítica, negligenciando a desigualdade econômica até então reverenciada pela Teoria Crítica como o principal empecilho à emancipação de cada indivíduo. Esse argumento é desconstruído por Honneth.

Honneth, divergindo de Nancy Fraser, entende a necessidade de redistribuição de renda e de redução da desigualdade social como mais uma demanda por reconhecimento de direitos, porque para ele “[...] a experiência de injustiça social sempre corresponde à demanda legítima por reconhecimento. Nessa perspectiva, a diferença entre desvantagem econômica e degradação cultural é fenomenologicamente secundária [...]" (HONNETH, 2003, p. 170)

A estrutura categórica da sua teoria do reconhecimento não diminuiria a importância da redução da desigualdade social. Desenvolvendo essa assertiva, Honneth passa a rebater a crítica a ele feita por Fraser, quando acusa a teoria crítica de se afastar de suas raízes e de se esquecer da desigualdade social que ainda afeta grande parte do mundo pós-moderno, "especialmente sob condições de neoliberalismo irrestrito” (FRASER, HONNETH, 2003, p. 112, tradução livre).

Para tanto, Honneth repete em “Redistribution or Recognition? A political-philosophical Exchange”, de 2003, a descrição da estrutura teórica da sua teoria do reconhecimento, apresentada em "Luta por Reconhecimento: a gramática moral dos conflitos”, publicada em 1992, traduzida em 2003 no Brasil.

4 A teoria do reconhecimento de Hegel é reconstruída por Axel Honneth em "Luta por reconhecimento: a gramática moral dos conflitos" (1993) e reformulada em "Direito da liberdade" (2015).

5 Interseccionalidades, interfaces, categorias de articulações, entrelaçamento de opressões são expressões dadas à categoria do pensamento feminista para designar a multiplicidade de discriminações decorrentes de diferentes fatores como gênero, raça, orientação sexual. 0 termo teria sido criado a partir de movimentos contra o racismo e a opressão masculina ainda antes da abolição da escravatura nos Estados Unidos (CRENSHAW, 2004). 
Ratifica a convicção na sua teoria, ponderando que o melhor modo de atualizar a Teoria Crítica para o mundo de hoje é orientá-la “[...] segundo uma estrutura categórica suficientemente diferenciada de teoria do reconhecimento, que estabeleça uma conexão entre as causas sociais que espalham sensação de injustiça aos objetivos normativos dos movimentos emancipatórios" (FRASER, HONNETH, 2003, p. 113, tradução livre).

Ele não enxerga uma ruptura entre demandas de reconhecimento e demandas materiais ou por redistribuição de riquezas, enxergando ambas como "resultado historicamente mutável do processo cultural de institucionalização” (FRASER; HONNETH, 2003, p.113, tradução livre), sendo a redução da desigualdade social uma injustiça que "deve ser entendida como expressão institucional de desrespeito, ou, melhor dizendo, de relações de reconhecimento injustificadas" (FRASER; HONNETH, 2003, p. 114, tradução livre).

Demandas por um meio ambiente equilibrado, por paz, por respeito ao multiculturalismo teriam evidenciado, a partir da década de 1980, para Honneth, que as demandas sociais não eram apenas relacionadas a bens materiais, mas, a algo superior, responsável por redirecionar o foco de descontentamento moral dos movimentos trabalhistas para um complexo de demandas difusas agrupado sob a denominação de "novos movimentos sociais".

Uma primeira crítica dirigida a Fraser, aponta-lhe uma falha teórica ao tratar a demanda por reconhecimento cultural ou reconhecimento de identidade como algo justificável em si, omitindo-se em explicar o motivo pelo qual determinadas demandas por reconhecimento cultural devem ser rechaçadas, em lugar de serem apoiadas por teoria de crítica social, tais como demandas por reconhecimento de grupos racistas ou nacionalistas tais como grupos neonazistas ou terroristas, como autoproclamado Estado Islâmico (FRASER; HONNET, 2003, p. 120-123, tradução livre)

De fato, se o reconhecimento de qualquer diferença identidária ou política pudesse estar embasado na Teoria do Reconhecimento, como parecia ser a visão de Fraser até então, movimentos racistas como o Ku Klux Klan ${ }^{6}$ nos Estados Unidos ou neonazistas no Brasil e até o terrorismo do autoproclamado Estado Islâmico encontrariam fundamento na teoria do reconhecimento para reivindicar o seu direito à diferença. Pelo contrário, a teoria do reconhecimento é substancial o suficiente para repelir esses grupos, não padecendo do mal de que é acusada pelo senso comum de ser tolerante com os intolerantes.

Isso porque a teoria do reconhecimento pensada por Axel Honneth somente admite como legítima a reivindicação por reconhecimento de uma diferença cuja presença prive o sujeito de direitos, excluindo-o de relações sociais. Não é qualquer reivindicação de diferença que encontra amparo na teoria do reconhecimento de Honneth, mas apenas aquela diferença que contenha uma expectativa legítima de pretensão normativa com validade para todos.

Em outras palavras, a diferença somente pode ser reconhecida como condição para que se seja tratado em igualdade recíproca. E como não há direito a excluir pessoas, maltratá-las, torturá-las e matá-las, essa diferença não é chancelada pela teoria do reconhecimento de Axel Honneth.

6 Organização terrorista fundada em 1865 no Tenessee, Estados Unidos, banida do país em 1872, reinstaurada em 1915. Seu nome é usualmente reivindicado em ataques racistas contra negros principalmente, mas também contra judeus, índios e católicos. Pregam a supremacia branca, a subordinação ou o extermínio de todas as raças exceto as autoconsideradas brancas e a exclusividade do protestantismo como religião (CAVALLARI, 2009, p. 1-2). 
Outra crítica é dirigida por Honneth a Charles Taylor, que enxergaria uma espécie de sucessão histórica de objetivos, sendo as sociedades liberal-capitalistas marcadas por lutas em busca de igualdade jurídica, estaria havendo uma substituição hoje por lutas em busca do reconhecimento de diferenças culturais. Para Honneth, não existe essa sucessão linear de movimentos sociais, porque tanto existiram lutas por reconhecimento cultural no passado como continuarão existindo lutas por igualdade jurídica no futuro (FRASER; HONNETH, 2003, p. 122-123, tradução livre).

Honneth qualifica a defesa de "políticas de identidade" ou de reconhecimento cultural ou de multiculturalismo de Fraser como "artefato sociológico". Para ele, a atualização da teoria do reconhecimento de Hegel não se esgota em uma moda de movimentos de política identitária, de gênero ou cultural. 0 resgate da teoria do reconhecimento é útil porque Honneth enxergou nela um "insight inexplorado das fontes motivacionais de descontentamento social e de resistência” (FRASER; HONNETH, 2003, p. 125, tradução livre).

A teoria crítica de Axel Honneth tenta, então, encontrar, a partir da reconstrução normativa ${ }^{7}$ das categorias hegelianas as "ferramentas teóricas" para determinar, do ponto de vista sociológico, o que é socialmente injusto (FRASER; HONNETH, 2003, p. 126, tradução livre).

Marx teria partido, segundo Honneth, de uma espécie de “utilitarismo antropológico" ao presumir e atribuir interesses racionais a um grupo inteiro de pessoas: o proletariado. Ele não se preocupou com as expectativas morais dos indivíduos e nem com a dimensão normativa que as frustrações dessas expectativas individuais poderiam criar (FRASER; HONNETH, 2003, p. 127, tradução livre).

Ocorre que para Honneth a noção de sofrimento é individual, podendo vir a ser normatizada como injustiça caso a expectativa frustrada por aquele sentimento de sofrimento e de desrespeito encontre eco na coletividade. Portanto, "o sentimento de injustiça social aparece quando faltam razões individualmente compreensíveis para determinada regra ou medida institucional” (FRASER; HONNETH, 2003, p. 129-130, tradução livre).

Além de individualmente incompreensível, a frustração gerada por essa incompreensão ou pela falta de justificativa plausível há de soar legítima para o resto da sociedade, a fim de que movimento emancipatório para a alteração normativa prospere. É nisto que está a reciprocidade da teoria: o questionamento do sistema normativo tem espaço para ocorrer "quando houver a frustração de expectativas consideradas legítimas ou quando as regras existentes consideradas legítimas forem aplicadas inadequada ou incorretamente" (FRASER; HONNETH, 2003, p. 157, tradução livre).

Mais tarde, no livro, Direto da Liberdade, Honneth reformula a sua teoria do reconhecimento a partir de uma atualização histórica do direito de liberdade e do exercício social da liberdade, dividindo-os em três fases: liberdade negativa, liberdade reflexiva e liberdade social. A liberdade jurídica e a

7 “[...] processo pelo qual se procura implantar as intenções normativas de uma teoria da justiça mediante a teoria da sociedade, já que valores justificados de modo imanente são, de maneira direta, tomados como fio condutor da elaboração [...] Com relação a esse processo, "reconstrução" deve significar que, tomando o conjunto das rotinas e instituições sociais, são escolhidas e representadas unicamente as que possam ser consideras indispensáveis para a reprodução social. E uma vez que os objetivos da reprodução devem ser estabelecidos em grande parte de acordo com os valores aceitos, a reconstrução “normativa" implica necessariamente ordenar as rotinas e instituições sob o ponto de vista da força de sua contribuição quanto à divisão do trabalho, para a estabilização e implantação daqueles valores (HONNETH, 2015, p. 24-25). 
liberdade moral seriam apenas possibilidades de liberdade, enquanto a liberdade social seria a realidade da liberdade que forneceria as expectativas normativas legítimas para a reconstrução normativa do direito e da moral (HONNETH, 2012).

Assim, enquanto Nancy Fraser entende que redistribuição e reconhecimento são instrumentos para se atingir a "paridade de participação", Axel Honneth parte da premissa de que a formação da identidade do ser humano se dá intersubjetivamente e depende da realização de reconhecimento em três esferas: amor (amizade), direito (mercado) e sociedade (vida pública-democrática), que acontecem intersubjetivamente na liberdade social ou na realidade da liberdade.

A realidade da liberdade informará ao indivíduo e à sociedade em quais dessas esferas falta reconhecimento a ser buscado pela luta, na primeira versão da teoria, ou pela formação da vontade democrática, na segunda versão. Faltará reconhecimento, a ser reivindicado por lutas sociais e/ou por reconstruções normativas do direito e da moral, sempre que faltar reconhecimento recíproco no amor/amizade; e/ou quando for privado de direitos ou excluído ou discriminado nas relações econômicas (trabalhista e consumeiristas) de mercado; e/ou quando for socialmente humilhado ou quando for excluído ou preterido da vida pública democrática ${ }^{8}$.

Se por um lado Axel Honneth responde a Nancy Fraser que a teoria do reconhecimento é mais do que um fundamento para o reconhecimento de diferenças culturais, estando estruturada como uma teoria de justiça, o argumento de Nancy Fraser permanece persuasivo, no sentido de que é mais simples pensar em redistribuição de renda para redução de desigualdades socioeconômicas e em direito a reconhecimento da diferença para redução de discriminações de gênero.

\section{RECONHECIMENTO, REDISTRIBUIÇÃO E REPRESENTACÇ̃̃O}

Influenciada ou não pelas críticas de Axel Honneth, o fato é que Nancy Fraser reformulou seu conceito de Justiça no livro Escalas de Justiça, de 2008, anos após esse debate, portanto ${ }^{9}$. Da mesma forma como Axel Honneth reformulou sua teoria do reconhecimento pela atualização histórico do direito e do exercício da liberdade em Direito da Liberdade, de 2012.

A liberdade social, de Axel Honneth, enquanto espaço de realização da liberdade do qual emergem novas reivindicações e que, ao mesmo tempo, assimila as reconstruções decorrentes das conquistas das reivindicações se assemelha à ideia de "dimensão política da justiça” de Nancy Fraser, no sentido de que, muito grosseiramente, ambos buscam, com essas categorias, definir a justiça como o

8 No primeiro livro de Axel Honneth, "Luta por reconhecimento: uma gramática moral dos conflitos sociais" (1993), o amor é identificado com o amor entre mãe e filho; a segunda esfera é identificada com o direito e a terceira, com a solidariedade social. No segundo livro, "Direito da Liberdade" (2015) Honneth amplia essa esfera para o amor das relações pessoais de amizade ou de intimidade; o direito passa a ser possibilidade de liberdade e o mercado passa a ser a segunda esfera do reconhecimento. Do mesmo modo, a solidariedade social passa a ser possibilidade de liberdade e a terceira esfera de reconhecimento passa a ser a esfera-pública democrática.

9 A versão consultada foi espanhola, publicada em 2012. A versão original foi publicada em 2008, cinco anos após o debate com Axel Honneth. 
exercício de dimensões equiparadas de liberdade entre os indivíduos em diversas esferas ou relações sociais, desde as relações pessoais, passando pelas trabalhistas e consumeiristas até as relações travadas na vida pública ou no espaço político.

Em Escalas de Justiça, Nancy Fraser defende que não existe mais uma compreensão compartilhada de justiça, como entendia haver nos anos 1960 e 1970 acerca da redistribuição de renda e nos anos 1980 e 1990, em torno do conceito reconhecimento das diferenças culturais.

Diferentemente do século $X X$, em que os militantes de movimentos sociais militavam por uma justiça como redistribuição, os reivindicantes de hoje militam em diferentes idiomas por objetivos rivais, sendo o espaço público disputado por demandas de grupos minoritários que lutam por reconhecimento de sua identidade de gênero, etnia, tradições culturais.

O resultado seria para Fraser uma heterogeneidade do discurso sobre justiça, que passa então a questionar quais são os critérios de justiça capazes de orientar decisões imparciais para reivindicações tão heterogêneas. Contextualizando-se em meio a tantas diferenças, Fraser propõe, agora, não mais dois critérios, como antes, mas, sim, três critérios de justiça: redistribuição, reconhecimento e representação.

Não haveria mais compartilhamento de premissas ontológicas sobre o conteúdo de justiça, de modo que o debate deixaria de girar em trono do quanto distribuir para passar a discutir qual critério de justiça - redistribuição, reconhecimento ou representação - deve ser utilizado para resolver cada conflito e de que modo, devendo-se passar a questionar "[...] dado esse choque entre concepções rivais quanto a substância da justiça, cada uma delas informada à sua maneira com seu conjunto próprio de balanças, como devemos decidir que tipo de balança utilizar em um determinado caso?” (FRASER, 2012, p. 155).

Portanto, é como se Fraser defendesse que cada tempo histórico-político esteve marcado por um conteúdo de justiça, mais ou menos uniforme e consentâneo, sendo o questionamento sobre a substância da justiça algo peculiar ao momento contemporâneo, surgido a partir do final do século XX. Diferentemente de Axel Honneth, que entende a justiça como o reconhecimento das condições necessárias à interação em igualdade de valor e de liberdade (HONNETH, 2015).

Em que pese aludir à teoria tridimensional de justiça, formada pela redistribuição, reconhecimento e representação, Nancy Fraser revela tanto em seu livro-debate com Axel Honneth quanto em Escalas de Justiça que tal teoria tridimensional de justiça deve conduzir à "paridade de participação" entre as pessoas. Ou seja, o "quê", o "quem" e o "como", definem elementos que devem ser analisados e ponderados para que se realize a "paridade de participação".

Sob essa perspectiva, a teoria tridimensional da justiça de Nancy Fraser se assemelha à teoria do reconhecimento de Axel Honneth, cujo conceito de justiça também está orientado para o atingimento de um tratamento recíproco que proporcione igual liberdade de ação às partes.

Nancy Fraser, usando a figura da balança e do mapa cartográfico, sintetiza seu problema de trabalho do seguinte modo, “[...] a problemática da balança, portanto, a questão central é o "quê" há que ser considerado como genuíno assunto de justiça. No mapa, pelo contrário, a questão é "quem" conta como autêntico sujeito de justiça" (FRASER, 2012, p. 191).

A dimensão política é acrescentada como campo de análise social, antes restrito às dimensões econômica e cultural ou social. Essa terceira dimensão tem por critério de aferição a "representação", assim “[...] chegar-se-á ao 'como’, para em seguida afirmar uma troca de paradigma: aquilo que o mar- 
co westfaliano-keynesiano proclama como teoria da justiça social deve agora se converter em teoria da justiça democrática postwestfaliana” (FRASER, 2012, p. 396, tradução livre).

Centrada em questões de pertencimento e de procedimento, a dimensão política de justiça se interessa sobretudo pela representação (FRASER, 2012, p. 427).

No primeiro nível, o do pertencimento, verifica-se o campo dos incluídos no direito de dirigir reivindicações mútuas. Trazendo para a realidade do Brasil, quanto ao sufrágio universal, homens e mulheres estão igualmente incluídos nesse primeiro nível, porque o voto é universal e individual, artigos 14 , caput, e $60, \S 4^{\circ}$, II, da CF.

O nível do pertencimento da dimensão política corresponde ao "quem”, à definição dos sujeitos titulares de direitos. Estes deixariam de ser determinados pelo território dos Estados para serem determinados pelo "princípio da afetação", de modo que, sujeito de direito é qualquer pessoa física ou jurídica de qualquer lugar do mundo que se relacione a um ato ou fato. Em síntese, titulares de direitos não são apenas os cidadãos de um estado, mas qualquer pessoa do mundo "afetada” pela situação.

Nancy Fraser, trazendo o "mapa” para as lutas feministas, conclama os movimentos feministas a incluírem não apenas as europeias e norte-americanas, mas toda a sorte de imigrantes como também todas as residentes fora desses territórios, como na América do Sul, África, Oriente Médio:

O resultado é uma nova fase da política feminista em que a justiça de gênero está sendo reenquadrada. Nesta fase, uma preocupação maior é com o desafio às injustiças - interligadas - de má distribuição e não-reconhecimento. Acima e além dessas formas de injustiça, feministas estão mirando uma meta-injustiça que apenas recentemente se tornou visível, a que eu chamo de mau enquadramento. 0 mau enquadramento surge quando o quadro do Estado territorial é imposto a fontes transnacionais de injustiça. Como resultado, temos divisão desigual de áreas de poder às expensas dos pobres e desprezados, a quem é negada a chance de colocar demandas transnacionais. Em tais casos, as lutas contra a má distribuição e o não-reconhecimento não são levadas adiante, e menos ainda são bem-sucedidas, a não ser que se liguem a lutas contra o mau enquadramento. 0 mau enquadramento, assim, emerge como alvo central da política feminista na sua fase transnacional. (FRASER, 2007, p. 304-305, grifo do autor).

Na esteira da defesa de diluição de fronteiras terrestres de Estados Nação pela globalização, Fraser também entende que as lutas feministas devem incluir todas as "afetadas" pela discriminação ou desigualdade em razão do gênero, abarcando, assim, todas as mulheres do mundo (FRASER, 2012, p. 2340). A dimensão política do pertencimento especifica o alcance das outras duas dimensões: ela informa "quem" está incluído e "quem" está excluído do círculo dos que tem direito a uma justa distribuição e ao reconhecimento recíproco (FRASER, 2012).

Mas a dimensão política também é determinante para a justiça por conter os procedimentos institucionalizados para resolver os conflitos das outras duas dimensões, a econômica e a cultural ou social: ela informa não apenas "quem" pode reivindicar redistribuição e reconhecimento, mas também "como" hão de se situar e se resolver essas reivindicações. 
O segundo nível, o do procedimento, verifica em que medida as regras de decisão que estruturam os processos públicos de confrontação incluem ou não os sujeitos. Trata-se de verificar as condições sob as quais se dá a disputa. Ele mede se, e até que ponto, são justas as regras de representação. Conceitualmente distintas de questões econômicas e sociais, não podem reduzir-se a elas, ainda que sejam interligadas intrinsecamente. Significa que a dimensão política pode dar ensejo a uma injustiça conceitualmente distinta, injustiça política.

No Brasil, a discussão sobre cotas para mulheres em partidos políticos e no Congresso Nacional toca o "quê" da representação, que definirá “quem” estabelecerá as normas legais que regerão "como" deve tramitar o processo legislativo e os demais processos de negociação ou estabelecimento de direitos, como o próprio processo judicial.

Nesse sentido, o art. 10, § $3^{\circ}$ da Lei no 9.504, de 1997, com redação dada pela Lei n 12.034, de 2009, determina que no mínimo $30 \%$ dos registros de candidaturas de partidos ou coligações para Câmara dos Deputados, Câmara Legislativa, Assembleias Legislativas e Câmaras Municipais devem ser formados por candidatos do mesmo sexo e no máximo $70 \%$ devem ser ocupados por candidatos do outro sexo.

A norma, todavia, não foi suficiente para garantir essa proporção da representatividade, por exemplo, na Câmara de Deputados, onde nas eleições de 2018, o número de mulheres subiu apenas de $10 \%$ para $15 \%$ em relação à legislatura anterior (BRASIL, 2018).

A proporção legal pode não ter sido atingida por uma falta de reconhecimento da identidade de gênero ou por um desconhecimento da importância da representatividade para a igualdade de gênero, mas também pode ter sido causada por mecanismos anteriores às eleições, como a formação de coligações por partidos sem o cumprimento da cota mediante a utilização de partidos pequenos apenas para cumprir o requisito legal.

Segundo o Tribunal Superior Eleitoral, esse comportamento passa a ser proibido a partir das Eleições 2020, em decorrência da entrada em vigor da Emenda Constitucional nº 97, de 2017, que proíbe a formação de coligações para as eleições proporcionais, como são as eleições para a Câmara de Deputados (BRASIL, 2019).

Sob essa perspectiva do "como" é de se cogitar a possibilidade de reivindicação de cotas para mulheres nos órgãos colegiados de decisão do Poder Judiciário, por exemplo, e sob a perspectiva do "quem" é de se cogitar até que ponto mulheres que vivem na China ou no Oriente Médio podem reivindicar a titularidade de liberdades individuais usufruídas pelas mulheres no ocidente. Portanto, o terceiro critério de justiça, a "representação política”, mede a paridade de participação na "dimensão política", circunscrevendo o "quem" e o "como" da justiça.

Uma das diferenças entre as teorias se encontra no método e na categorização, parecendo a estrutura de Axel Honneth mais sólida, uma vez que a teoria de Nancy Fraser parece necessitar abrir espaço para agregação de novos critérios de justiça a cada necessidade ou direito a ser reivindicado de acordo com novos padrões culturais ou morais. 0 risco ou a falha desse método de Fraser é, para Axel Honneth, estar sempre categorizando os anseios sociais e as injustiças após elas virem a público pelos meios de comunicação, dando uma justificativa aos movimentos sociais após eles virem à tona (FRASER; HONNETH, 2003, p. 136). 
Para Axel Honneth, uma teoria social deve indicar caminhos para evitar novas injustiças no futuro a partir da análise da realidade presente. Ao pressupor que a justiça depende do reconhecimento recíproco nas esferas do amor, do direito ou social, sua teoria sustenta novas e diferentes reivindicações sociais ${ }^{10}$.

A teoria do reconhecimento de Axel Honneth não se esgota na aceitação das diferenças culturais, como parece ser a leitura de Nancy Fraser, mas ela pressupõe que a realização da autonomia do indivíduo depende de experiências de reciprocidade no amor, no direito e na estima social, gerando autoestima, autorrespeito e autorrealização.

A carência afetiva por que passariam as mulheres emancipadas nessa terceira fase do feminismo, na visão de Nancy Fraser, comentada na seção 1, estaria "prevista" ou "contemplada" pela teoria do reconhecimento de Axel Honneth, porque ela pressupõe a realização no amor e na esfera valorativa social como esferas do reconhecimento necessárias à emancipação ou à autonomia do indivíduo.

Tem-se, aplicando a teoria do reconhecimento de Axel Honneth para tentar solucionar a preocupação de Fraser quanto à necessidade de segurança emocional ou acolhimento da mulher na terceira fase do reconhecimento, que os movimentos feministas poderiam estar orientados, nesse momento, não mais apenas para a busca de direitos, mas para a solidariedade social ou para as relações sociais como a amizade, que pode ser operacionalizado, por exemplo, pela criação de grupos de apoio psicológicos, terapêuticos ou lúdicos para as demandas femininas captadas por Fraser. Algo que soa como sororidade.

Logo, seria nas primeira e terceira esferas do reconhecimento de Axel Honneth, respectivamente, a amizade e a solidariedade, que a "insegurança emocional da mulher empoderada do mundo capitalista neoliberal”, diagnosticada por Nancy Fraser, poderia encontrar o reconhecimento faltante ou a paridade de participação.

\section{CONCLUSÕES}

Nancy Fraser entende que a segunda onda do feminismo, enquanto movimento social orientado pela busca pela igualdade de gênero, que teve início nos Estados Unidos e na Europa Ocidental entre 1960 e 1970, reivindicou um conceito próprio de justiça, diferente de uma balança voltada para a redistribuição de renda.

A segunda onda do feminismo teria sido uma das responsáveis por ressuscitar as teorias do reconhecimento de origem hegeliana, cujo manejo teria sido importante para o reconhecimento cultural da diferença e sua inclusão social e econômica. Detecta, ainda, que a terceira onda do feminismo não está sabendo responder à demanda por segurança, financeira e emocional, da mulher contemporânea, presa ao sistema capitalista neoliberal.

Na visão de Fraser, o reconhecimento é critério insuficiente para atender a todas as demandas femininas por justiça, pelo que elabora ou defende a utilização simultânea de três critérios de justiça:

10 Em o "Direito da Liberdade” a teoria do reconhecimento é modificada e as esferas sociais passam a ser relações íntimas ou pessoais, o mercado e a vida pública-democrática, mas tais alterações não implicam uma mudança no teor da discussão com Nancy Fraser a respeito de reconhecimento e redistribuição. 
redistribuição, reconhecimento e representação, capazes de definir o "quê", o "quem" e o "como" da justiça. Defende ainda de que a ideia de balança é apenas uma faceta da justiça, que também exige a figura das escalas em um mapa mundial ou transnacional.

Contrariamente a Nancy Fraser, Axel Honneth parte da teoria do reconhecimento para elaborar uma teoria crítica do social, visando a emancipação da sociedade e de cada indivíduo em busca da maior inclusão de pessoas emancipadas, dotadas de liberdade igual para interagir em equidade.

A conquista da autonomia individual ou da autorrealização no exercício da "liberdade social" dependeria da experiência de reconhecimento recíproco em três esferas sociais sistematizadas em "Luta por reconhecimento: uma gramática moral dos conflitos sociais" e reformuladas em "Direito da liberdade". A primeira é a esfera das relações familiares e do amor, reformulada para amizade e relações íntimas; a segunda esfera é a esfera do direito, reformulada para as relações de mercado; a terceira esfera é a estima ou solidariedade social, reformulada para a vida pública democrática.

A falta de reconhecimento em cada uma dessas esferas deflagra lutas morais em forma de movimentos sociais ou debates democráticos para a reconstrução normativa da liberdade jurídica e da liberdade moral, as possibilidades de liberdade.

Assim, para Honneth, nem toda falta de reconhecimento se resolve na esfera do direito ou mediante uma conquista de direitos, como também o reconhecimento não se esgota na dimensão cultural, porque circula em todas as dimensões econômica, jurídica, moral, social.

Em conclusão, Axel Honneth cria categorias capazes de fundamentar novas demandas enquanto Nancy Fraser parece criar categorias para justificar demandas já existentes e reforçar a ação social. Ambos, juntos, permitem que se repense o papel dos movimentos feministas de terceira onda, que poderia atender à demanda por segurança emocional da mulher contemporânea nas esferas da amizade e da solidariedade.

\section{REFERÊNCIAS}

ASSMANN, Selvino José. Apresentação e tradução da Declaração dos Direitos da Mulher e da Cidadã de Olympe de Gouges. Revista Internacional Interdisciplinar Interthesis, Florianópolis, v. 4, n. 1, jan.-jun. 2007. Disponível em: https://periodicos.ufsc.br/index.php/interthesis/article/ view/54986/35894. Acesso em: 3 dez. 2019

BRASIL. Câmara De Deputados. Bancada feminina na Câmara sobre de 51 para 77 deputadas. Comunicação, Notícias, Política e Administração Pública, 8 out. 2018. Disponível em: https:// www.camara.leg.br/noticias/545897-bancada-feminina-na-camara-sobe-de-51-para-77deputadas/. Acesso em: 30 jan. 2020

BRASIL. Casa Civil. Lei 9.504, de 30 de setembro de 1997. Disponível em: http://www.planalto.gov. br/ccivil_03/leis/l9504.htm. Acesso em: 20 jan. 2020 
BRASIL. Tribunal Superior Eleitoral. Cota de 30\% para mulheres nas eleições proporcionais deverá ser cumprida por cada partido em 2020. Comunicação, Notícias, 8 mar. 2019. Disponível em: http://www.tse.jus.br/imprensa/noticias-tse/2019/Marco/cota-de-30-para-mulheres-nas-eleicoesproporcionais-devera-ser-cumprida-por-cada-partido-em-2020. Acesso em: 30 jan. 2020

CAVALLARI, Orlando. Terrorismo doméstico e violência urbana no Brasil e nos Estados Unidos da América: um estudo comparativo das organizações Ku Klux Klan e Skin Red. Poliarquia Revista de Estudos Políticos e Sociais, Centro Universitário Unieuro, Brasília, v. 1, n.2, jul.-dez. 2009. Disponível em: www.uniero.edu.br/sitenovo/revistas/downloads/poliarquia_02_007.pdf. Acesso em: 2 fev. 2020

CRENSHAW, Kimberle. A intersecionalidade na discriminação de raça e gênero. In: VV.AA.

Cruzamento Raça e gênero. Brasília: Unifem, 2004. Disponível em: http://www.acaoeducativa.org. br/fdh/wp-content/uploads/2012/09/Kimberle-Crenshaw.pdf. Acesso em: 20 jan. 2019

FERREIRA, Maria Mary. Apresentação do dossiê: feminismos, política e Lutas Contemporâneas das Mulheres. Revista Debates Insubmissos, Caruaru-PE. Brasil, Ano I, v. 1, n. 2, maio-ago. 2018. Disponível em: https://periodicos.ufpe.br/revistas/debatesinsubmissos/. Acesso em: 20 jan. 2020.

FRASER, Nancy; HONNETH, Axel. Redistribution or Recognition? A political-philosofical exchange/ Nancy Fraser and Axel Honneth; translated by Joel Golb, James Ingram, and Christiane Wilke. London. New York: Verso, 2003.

FRASER, Nancy; HONNETH, Axel. Mapeando a imaginação feminista: da redistribuição ao reconhecimento e à representação. Revista Estudos Feministas, Florianópolis, v. 15, n. 2, maio-ago. 2007. Disponível em: http://www.scielo.br/scielo.php?script=sci_arttext\&pid=S0104026X2007000200002. Acesso em: 20 jan. 20

FRASER, Nancy; HONNETH, Axel. O feminismo, o capitalismo e a astúcia da História. Trad. Anselmo da Costa Filho e Sávio Cavalcante. Mediações - Revista de Ciências Sociais, Londrina, v. 14, n. 2, p. 11-33, jul. dez. 2009. Disponível em: http://www.uel.br/revistas/uel/index.php/mediacoes/article/ view/4505/3782. Acesso em: 20 jan. 2019.

FRASER, Nancy; HONNETH, Axel. Escalas de Justicia. Trad. Antoni Martínez Riu. Barcelona: Herder Editorial, 2012.

HONNETH, Axel. Luta por reconhecimento: a gramática moral dos conflitos. São Paulo: Martins Fontes, 2003.

HONNETH, Axel. 0 direito da liberdade. Trad. Saulo Krieger. São Paulo: Martins Fontes, 2015. 
TEIXEIRA, Ana Carolina Brochado; RODRIGUES, Renata de Lima. A travessia da autonomia da mulher na pós-modernidade: da superação de vulnerabilidades à afirmação de uma pauta positiva de emancipação. Revista Pensar, Fortaleza, v. 23, n. 3, p. 1-20, jul.-set. 2018. Disponível em: https:// periodicos.unifor.br/rpen/article/view/7777/pdf. Acesso em: 20 jan. 2020

SANTOS, Simone Maria dos; MOURA, Nayara Aparecida de. O feminismo de primeira onda no interior de Minas Gerais pelas Mãos de Maria de Lourdes Teixeira. Revista Debates Insubmissos, Caruaru-PE. Brasil, Ano I, v. 1, n. 2, maio-ago. 2018. Disponível em: https://periodicos.ufpe.br/ revistas/debatesinsubmissos/ Acesso em: 20 jan. 2020 
1 Especialista em Direito Tributário - IBET/DF; Mestranda em direito, Universidade Federal de Sergipe - UFS.

E-mail: ariellafm@hotmail.com

2 Especialista em Direito Tributário - IBET/DF; Mestranda em direito, Universidade Federal de Sergipe - UFS.

E-mail: ariellafm@hotmail.com

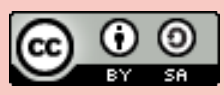

Este artigo é licenciado na modalidade acesso abertosob a Atribuição-Compartilhalgual CC BY-SA

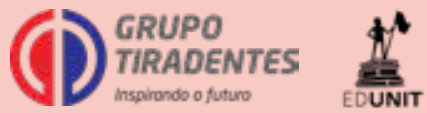

